\title{
Phospholipase D promotes Arcanobacterium haemolyticum adhesion via lipid raft remodeling and host cell death following bacterial invasion
}

\author{
Erynn A Lucas ${ }^{1,4}$, Stephen J Billington ${ }^{1,5}$, Petteri Carlson², David J McGee ${ }^{3 *}$, B Helen Jost ${ }^{1,6}$
}

\begin{abstract}
Background: Arcanobacterium haemolyticum is an emerging bacterial pathogen, causing pharyngitis and more invasive infections. This organism expresses an unusual phospholipase D (PLD), which we propose promotes bacterial pathogenesis through its action on host cell membranes. The pld gene is found on a genomic region of reduced $\% \mathrm{G}+\mathrm{C}$, suggesting recent horizontal acquisition.

Results: Recombinant PLD rearranged HeLa cell lipid rafts in a dose-dependent manner and this was inhibited by cholesterol sequestration. PLD also promoted host cell adhesion, as a pld mutant had a $60.3 \%$ reduction in its ability to adhere to HeLa cells as compared to the wild type. Conversely, the pld mutant appeared to invade HeLa cells approximately two-fold more efficiently as the wild type. This finding was attributable to a significant loss of host cell viability following secretion of PLD from intracellular bacteria. As determined by viability assay, only 15.6\% and $82.3 \%$ of HeLa cells remained viable following invasion by the wild type or pld mutant, respectively, as compared to untreated HeLa cells. Transmission electron microscopy of HeLa cells inoculated with A. haemolyticum strains revealed that the pld mutant was contained within intracellular vacuoles, as compared to the wild type, which escaped the vacuole. Wild type-infected HeLa cells also displayed the hallmarks of necrosis. Similarly inoculated HeLa cells displayed no signs of apoptosis, as measured by induction of caspase 3/7, 8 or 9 activities.

Conclusions: These data indicate that PLD enhances bacterial adhesion and promotes host cell necrosis following invasion, and therefore, may be important in the disease pathogenesis of A. haemolyticum infections.
\end{abstract}

\section{Background}

Arcanobacterium haemolyticum is a gram positive, nonmotile rod originally identified as a cause of pharyngitis and wound infections in U.S. servicemen and Pacific islanders $[1,2]$. A. haemolyticum is almost exclusively a human pathogen, making it somewhat unique within the genus [3]. The other species are uncommonly isolated, with the exception of Arcanobacterium pyogenes, which is an economically important opportunistic pathogen of livestock [3].

A. haemolyticum pharyngitis is a disease of adolescents and young adults, with $>90 \%$ of cases occurring in patients between 10-30 years of age [4-6]. Clinically, $A$.

\footnotetext{
* Correspondence: dmcgee@|suhsc.edu

${ }^{3}$ Department of Microbiology and Immunology, Louisiana State University Health Sciences Center-Shreveport, 1501 Kings Highway, Shreveport, LA 71130, USA

Full list of author information is available at the end of the article
}

haemolyticum pharyngitis resembles that caused by Streptococcus pyogenes, although in $33-66 \%$ of cases, an erythematous rash occurs after onset [5,7]. More rarely, A. haemolyticum is responsible for invasive diseases such as meningitis [8], septic arthritis [9], and osteomyelitis [10]. Invasive infections occur in older patients $(>30$ years) who may be immunocompromised or have other co-morbid factors $[11,12]$. However, invasive infections also occur in younger, immunocompetent patients (1530 years), who often have a prior history of upper respiratory tract disease (pharyngitis, sinusitis) due to $A$. haemolyticum $[12,13]$. This suggests that invasion of the organism to distal sites may occur from the initial site of infection in the nasopharynx.

Little is known about $A$. haemolyticum virulence factors and consequently, the mechanisms of pharyngeal infection and dissemination into deeper tissues remain to be elucidated. Initial virulence studies were performed by
C Biomed Central

() 2010 Lucas et al; licensee BioMed Central Ltd. This is an Open Access article distributed under the terms of the Creative Commons Attribution License (http://creativecommons.org/licenses/by/2.0), which permits unrestricted use, distribution, and reproduction in any medium, provided the original work is properly cited. 
intradermal injection of bacteria into humans, guinea pigs and rabbits, resulting in elevated abscesses with necrosis and a pronounced neutrophil infiltration 24-48 hours post infection [2]. However, attempts to induce pharyngitis by inoculation of bacteria onto the human pharynx were unsuccessful [2]. Intravenous inoculation of $A$. haemolyticum into rabbits resulted in hemorrhagic pneumonia [2], suggesting this organism can cause invasive disease once it enters the bloodstream. Subsequently, a phospholipase D (PLD) was identified and shown to cause the dermonecrosis observed [14]. While the role of A. haemolyticum PLD in pathogenesis is currently unclear, PLD is expressed during infection, as determined by the presence of serum antibodies in pharyngitis patients $[15,16]$.

PLDs are ubiquitous enzymes which cleave phospholipids, including phosphatidylcholine (PC) and sphingomyelin (SM), both of which are abundant in the mammalian plasma membrane [17]. SM, with cholesterol and GPI-anchored proteins, predominantly partitions to lipid rafts, which are tightly packed, membrane micro-domains that act to compartmentalize cellular processes on the outer leaflet of the plasma membrane [18]. Lipid rafts are also implicated in host cell invasion by microorganisms [19]. Host PLD cleaves SM releasing ceramide and accumulation of ceramide within rafts alters their biophysical properties, leading to the formation of large, ceramide-rich membrane platforms [20]. These platforms allow reorganization and aggregation of protein receptors and receptor-associated signaling molecules, which in turn facilitates efficient signal transduction for normal physiological processes [20]. In contrast, PC found in the liquid disordered, or non-raft, phase, is associated with both the inner and outer membrane leaflets, and is cleaved by PLD to phosphatidic acid and choline, which also have roles as second messengers [18].

PLD is the only $A$. haemolyticum virulence factor cloned and sequenced to date [21]. Almost invariantly, PLDs possess two His-X-Lys- $\mathrm{X}_{4}$-Asp (HKD) motifs that are involved in catalysis [22]. However, the PLD expressed by $A$. haemolyticum is not related to these more common HKD PLDs and has a limited substrate specificity which includes SM, but not PC [23], leading to the alternate nomenclature, sphingomyelinase D. Unlike host sphingomyelinases, A. haemolyticum PLD cleaves SM releasing ceramide-1- $\mathrm{PO}_{4}$ instead of ceramide. Like ceramide, ceramide-1- $\mathrm{PO}_{4}$ is a bioactive sphingolipid, and it acts as a signaling molecule involved in regulating critical cell functions [24].

A. haemolyticum PLD is most closely related to the PLD of Corynebacterium pseudotuberculosis [21]. In C. pseudotuberculosis, PLD is absolutely required for virulence, as a pld mutant could not spread from the site of inoculation or persist in the lymph nodes [25]. C. pseudotuberculosis PLD hydrolyzes SM in host cell membranes and lysophosphatidylcholine in plasma [23], which causes endothelial membrane leakage and cytolysis, leading to enhanced vascular permeability [25]. C. pseudotuberculosis PLD also activates complement [26], promotes neutrophil chemotaxis [27] and is directly dermonecrotic when injected into the skin [26]. The PLDs of recluse spider (Loxosceles spp.) venom are also structurally and functionally related to the A. haemolyticum and corynebacterial PLDs [28]. Purified spider PLD induces intravascular hemolysis and cytokine upregulation [29], dermonecrosis [30], and complement-mediated lysis of erythrocytes [26].

PLD expression is uncommon among other bacterial pathogens and these PLDs are exclusively of the HKD superfamily. However, most of the pathogens that do express PLD have obligate or facultative intracellular lifestyles and expression of this enzyme is thought to be involved in disease pathogenesis [31-35]. Specifically in Neisseria gonorrhoeae and Rickettsia spp., PLDs are required for invasion of host cells [32,35].

This work characterizes the effects of $A$. haemolyticum PLD on host cells, with an aim to elucidating the role of this toxic enzyme in disease pathogenesis. We report that PLD is required for optimal adhesion to host cells, via remodeling of lipid rafts. Furthermore, PLD expressed inside host cells is directly toxic, leading to cell death via necrosis. These findings provide the first conclusive evidence that PLD may be required for $A$. haemolyticum disease pathogenesis.

\section{Results}

\section{Analysis of the pld gene region}

A draft genome sequence of $A$. haemolyticum ATCC9345 was determined (B.H. Jost and S.J. Billington, unpublished data), and this data was used to identify sequences flanking the pld gene (GenBank Accession Number L16583). The pld gene was found in a region resembling a 1.9-kb genomic island of lower $\% \mathrm{G}+\mathrm{C}$ than the rest of the A. haemolyticum genome (53.1\%). This region consists of pld $(47.2 \% \mathrm{G}+\mathrm{C})$, and orf489 $(50.3 \% \mathrm{G}+\mathrm{C})$ which lacks a signal sequence and is of unknown function (Figure 1). 43-bp downstream of pld and 17-bp upstream of orf489 is a stem-loop structure with a $\Delta \mathrm{G}=$ $-20.8 \mathrm{kcal} / \mathrm{mol}$, which may act as a transcriptional terminator or attenuator. There does not appear to be any direct or indirect repeats flanking this region. The pld region is flanked upstream by three tRNA genes and gluRS, encoding a glutamyl-tRNA synthetase (EC 6.1.1.17), and downstream by $d c p$, encoding a peptidyldipeptidase (EC 3.4.15.5), which is divergently transcribed compared to pld (Figure 1). The $\% G+C$ of the 


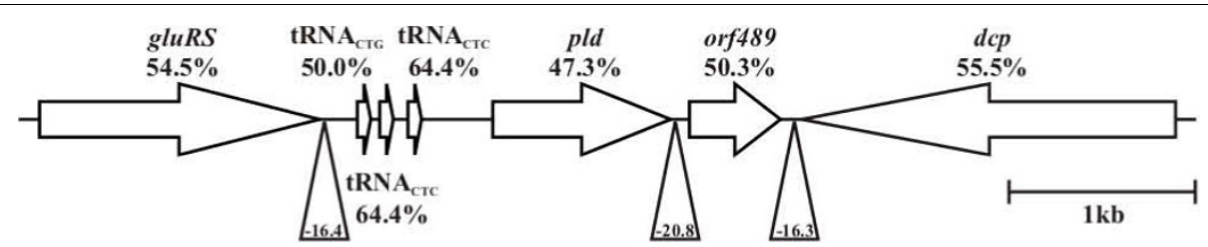

Figure 1 Map of the pld gene region. The open arrows indicate genes and the direction of transcription. Triangles below the sequence indicate the location of stem-loop structures, with the $\Delta \mathrm{G}(\mathrm{kcal} / \mathrm{mol})$ shown inside the triangle. Gene names are given above or below the arrows and the number below the name indicates the $\% \mathrm{G}+\mathrm{C}$ of the gene. $\mathrm{A}$ bar indicating $1-\mathrm{kb}$ is shown on the right.

surrounding housekeeping genes (Figure 1) more closely resembles the $\% \mathrm{G}+\mathrm{C}$ of the $A$. haemolyticum genome.

Given the variation in $\% \mathrm{G}+\mathrm{C}$ of the pld gene and the presence of adjacent tRNA genes, which often act as sites of foreign gene insertion [36], it is possible that the A. haemolyticum pld gene was acquired by horizontal gene transfer. It would appear that orf 489 is also part of the transferred DNA, and while it is not translationally coupled to pld, its transcription may be linked to that of pld despite the presence of a transcriptional terminator/ attenuator between the two genes. While its function cannot be ascertained from database comparisons, it is not required for PLD activity, as this enzyme is functional when expressed from a recombinant plasmid lacking orf489, such as the one used as a complementing plasmid (see below).

\section{PLD is expressed by all isolates of $A$. haemolyticum}

The prevalence of the pld gene was determined by DNA hybridization using a pld-specific gene probe. The pld probe hybridized at high stringency to each of $52 \mathrm{~A}$. haemolyticum isolates, but not to A. pyogenes BBR1 (data not shown), indicating that pld is present in all strains. Furthermore, all 52 isolates express PLD as determined by a PLD activity assay (data not shown). Expression of PLD throughout the growth curve was also determined. PLD expression commenced as the bacteria entered log-phase and maximal expression was observed throughout logarithmic growth (data not shown).

\section{PLD stimulates lipid raft remodeling}

As PLD acts on SM which is abundant in host cell lipid rafts, we hypothesized that PLD may perturb these structures, which in turn, could exacerbate the A. haemolyticum disease process. HeLa cells were treated with purified HIS-PLD and the ability of this toxin to cause lipid raft rearrangement was assessed. Cells displaying punctate staining were considered positive for lipid raft rearrangement (Figure 2B), whereas cells displaying a diffuse staining pattern were considered negative (Figure 2A). 9.4\% of untreated, control HeLa cells displayed punctate staining (Figure 2C). Similarly, HeLa cells treated with HIS-protein purification buffer displayed similar levels of punctate staining as the control (data not shown). Upon addition of increasing amounts of HIS-PLD (0-50 ng), the number of cells with punctate staining significantly increased in a dose-dependent manner from $9.4 \%$ to $31.7 \%$ (Figure 2C).

The ability of anti-PLD antibodies to block PLDmediated lipid raft rearrangement was investigated. In the absence of PLD, addition of pre-immune or antiPLD serum did not significantly affect the number of punctate-staining cells compared to untreated HeLa cells (9.9\%; negative control; Figure 2D). In the presence of PLD, $26.0 \%$ of HeLa cells displayed punctate staining (positive control; $p<0.05$ compared to the negative control; Figure 2D). In the presence of PLD, addition of pre-immune serum did not significantly affect the number of punctate staining cells as compared to the positive control ( $p=0.25$; Figure 2D). In contrast, in the presence of PLD, the addition of anti-PLD antibodies significantly reduced the number of punctate staining cells $(p<0.05$ compared to the positive control; Figure 2D). Numbers of punctate staining cells under these conditions were not significantly different to untreated HeLa cells $(p=0.15$; Figure $2 \mathrm{D})$, indicating that the lipid raft rearrangement seen is specific to the action of PLD.

Cholesterol sequestration by $\mathrm{M} \beta \mathrm{CD}$ blocks lipid raft rearrangement by partially solubilizing GPI-anchored and transmembrane proteins [37] and preventing small lipid rafts from aggregating into larger, functional membrane platforms [20]. In the absence of PLD, only 9.9\% of HeLa cells displayed punctate staining (untreated negative control; Figure 2D). Treatment of HeLa cells with $5 \mathrm{mM} \mathrm{M} \beta C D$ significantly reduced the amount of punctate staining cells to $7.4 \%$ ( $p<0.05$ compared with the negative control; Figure 2D), indicating that spontaneous lipid raft rearrangement was being inhibited. In the presence of PLD, $26.0 \%$ of HeLa cells displayed punctate staining (positive control; $p<0.05$ compared to negative control; Figure 2D). Treatment of HeLa cells with $\mathrm{M} \beta \mathrm{CD}$ significantly reduced the level of punctate staining to $10.5 \%$ ( $p<0.05$ compared with the positive control; Figure 2D). This value is similar to the amount 

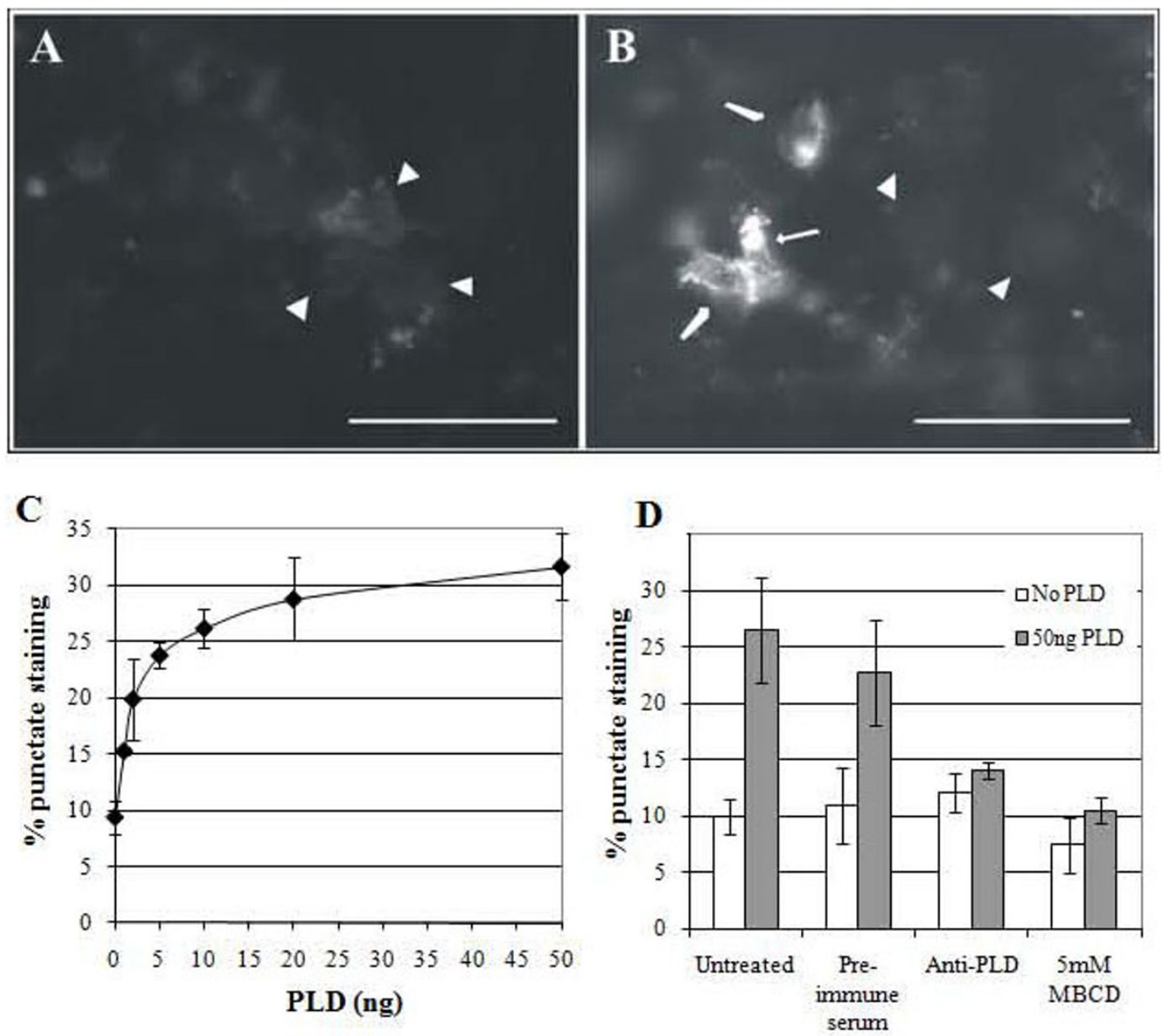

Figure 2 PLD stimulates the formation of lipid rafts in a dose-dependent manner. HeLa cells were treated (A) without or (B) with 50 ng PLD for 10 min at $37^{\circ} \mathrm{C}$ followed by staining with the Vybrant Lipid Raft Labeling Kit. The arrows indicate cells with bright, punctate staining, while the arrow heads indicate diffusely staining cells. Bar $50 \mu \mathrm{m}$. (C) HIS-PLD was added to HeLa cells for 10 min at $37^{\circ} \mathrm{C}$ prior to measurement of lipid raft formation. At least 100 cells were counted and the percentage of cells displaying punctate staining were enumerated. (D) Anti-PLD antibodies or the cholesterol sequestering agent MBCD inhibit PLD-mediated lipid raft formation. HeLa cells were untreated, or treated with $1 /$ 1000 dilutions of pre-immune or anti-PLD serum or $5 \mathrm{mM} \mathrm{M \beta CD}$ prior to addition of $50 \mathrm{ng}$ HIS-PLD and measurement of lipid raft formation. Untreated HeLa cells or those treated with pre-immune, anti-PLD serum or M $\beta C D$, but not HIS-PLD served as the negative controls. Error bars indicate one standard deviation from the mean calculated from the averages of at least three independent experiments conducted in triplicate. Statistical significance was calculated using single factor ANOVA and $p<0.05$ was considered significant.

of lipid raft rearrangement seen in negative control HeLa cells $(9.9 \% ; p=0.54$; Figure 2D). These data indicate that PLD-mediated lipid raft rearrangement can be inhibited by cholesterol sequestration.

\section{A. haemolyticum PLD is required for efficient bacterial adhesion to the host cell}

The ability of PLD to enhance lipid raft rearrangement may affect the interaction between the bacterium and the host cell. To test this hypothesis, wild type and pld mutant A. haemolyticum were assayed for their ability to adhere to HeLa cells. A pld mutant was constructed by allelic exchange and this mutant lost its hemolytic phenotype on TS agar containing 5\% bovine blood and 10\% Equi Factor.
Hemolysis was restored to wild type levels upon complementation with $\mathrm{pBJ} 61$, carrying the pld gene (data not shown). The hemolytic phenotype was not affected by the introduction of the shuttle vector alone (data not shown).

The ability of wild type or the pld mutants to adhere to HeLa cells was determined. Wild type A. haemolyticum adhered to HeLa cells at an average of $13.4 \%$ of the inoculum. This value was set at $100 \%$ and the adhesion of the other strains was determined as a percentage of wild type adhesion. The pld mutant was significantly impaired in adhesion, adhering at only $39.7 \%$ of the wild type $(p<0.05$; Figure 3A). Complementation of the pld mutant with pld in trans restored adhesion to $106.9 \%$ of wild type (Figure 3A). It should be noted that the assay 


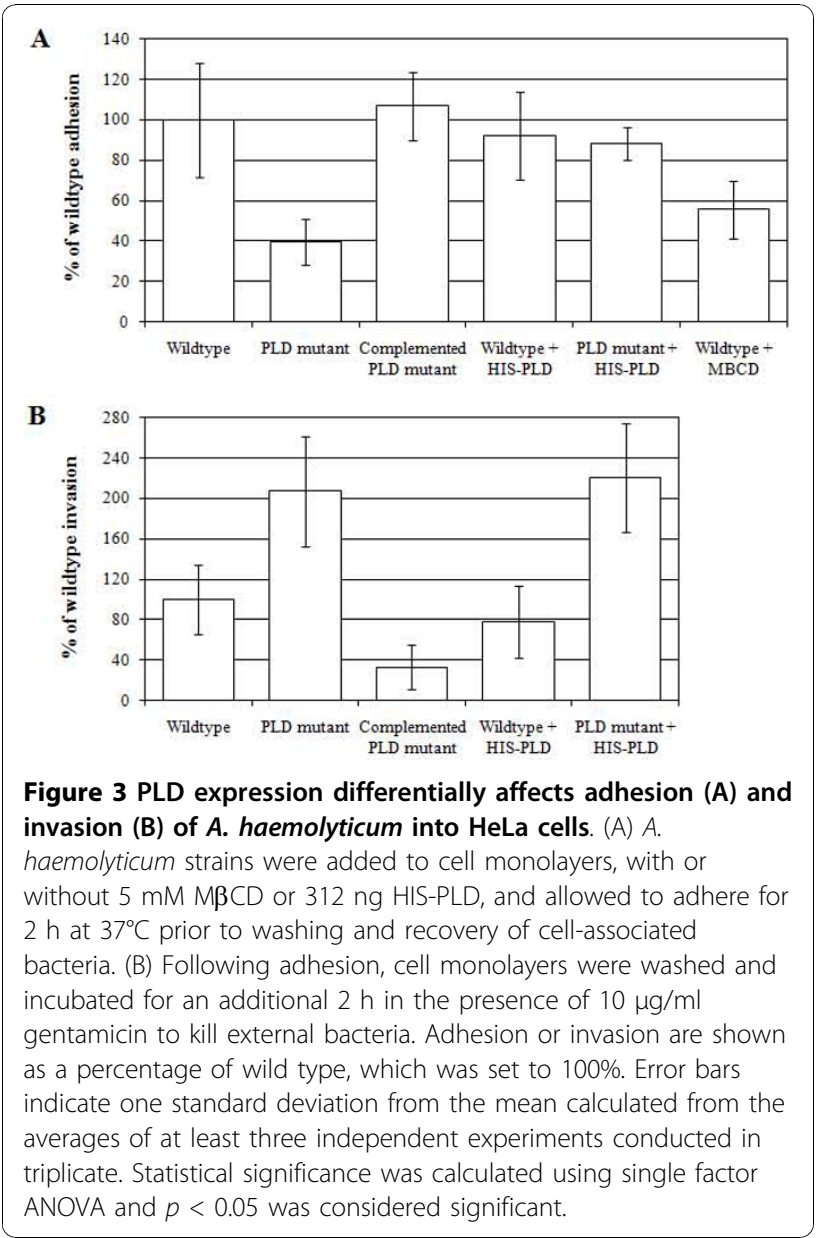

as performed measures both adhered bacteria and any that have subsequently invaded. However given that invasion follows bacterial adhesion, all cell-associated bacteria, whether internalized or on the cell surface, were at one point adherent to the host cell.

We hypothesized that $A$. haemolyticum PLD promoted bacterial adhesion to host cells via receptor clustering as a result of SM cleavage, leading to lipid raft signaling. Treatment of cells with $5 \mathrm{mM} \mathrm{M} \beta C D$ resulted in a $44.4 \%$ reduction in the adherence of wild type $A$. haemolyticum to HeLa cells, as compared to untreated controls $(p<0.05$; Figure 3A), indicating that the loss of lipid raft rearrangement directly affected the ability of $A$. haemolyticum to adhere to HeLa cells.

\section{A. haemolyticum lacking PLD appear to invade HeLa cells more efficiently}

The ability of wild type and pld mutants to invade host cells was also determined. Wild type A. haemolyticum invaded HeLa cells at an average of $0.24 \%$ of the adherent bacteria. This value was set at $100 \%$ and the invasion of the other strains was determined as a percentage of wild type invasion. The pld mutant was not impaired in invasion, and could invade significantly better at $207.1 \%$ of wild type A. haemolyticum $(p<0.05$; Figure $3 \mathrm{~B})$. Complementation of the pld mutant led to significantly more impaired invasion than the wild type (only $33.0 \%$ of wild type; $p<0.05$; Figure $3 \mathrm{~B}$ ), which probably results from a gene dosage effect of pld expressed from a multi-copy plasmid.

We also examined the effect of exogenously-added recombinant HIS-PLD on bacterial adhesion and invasion. HIS-PLD significantly enhanced the adhesion of the pld mutant and returned it to wild type levels $(p<$ 0.05 compared to the pld mutant without exogenous PLD; Figure 3A). Addition of exogenous PLD did not enhance adhesion of the wild type (Figure 3A), suggesting that under these conditions, the effect of PLD on wild type adhesion is at saturation. As the exogenouslyadded PLD is soluble and not bacterially-associated, this indicates that PLD cannot directly act as an adhesin. Bacterial invasion was not altered in the presence of exogenous PLD for either the wild type or pld mutant, suggesting that PLD does not play a direct role in invasion once the bacteria are adherent (Figure 3B).

HeLa cell viability is reduced following invasion by PLDexpressing $A$. haemolyticum

The viability of HeLa cells following invasion by $A$. haemolyticum strains was measured to determine whether PLD expressed intracellularly was cytotoxic. The viability of $A$. haemolyticum-inoculated HeLa cells was determined as a percentage of uninoculated HeLa cells, which was set at $100 \%$. Following invasion of host cells with wild type $A$. haemolyticum, only $15.6 \%$ of the HeLa cells remained viable after $5 \mathrm{~h}$, compared with uninoculated HeLa cells $(p<0.05$; Figure 4$)$. The pld mutant displayed significantly reduced cytotoxicity with $82.3 \%$ of HeLa cells viable, as compared to the uninoculated control ( $p<0.05$; Figure 4$)$. Invasion of HeLa cells with the complemented pld mutant resulted in $15.4 \%$ of HeLa cell viability, similar to that of the wild type (Figure 4). Initial measurements of HeLa viability at $2 \mathrm{~h}$ did not demonstrate a significant loss of host cell viability (data not shown). This is not unexpected, as time is required for the invaded bacteria to synthesize and express PLD, and for PLD to exert its effects leading to the end-stage, measurable outcome of loss of host cell viability.

These data indicated that invasion of HeLa cells by $A$. haemolyticum results in loss of host cell viability, with the majority of that being attributable to expression of PLD. Interestingly, when purified HIS-PLD was applied to the exterior of HeLa monolayers for 2-24 h, no HeLa cytotoxicity was detected over this time period, even at the highest concentrations of PLD (data not shown). 


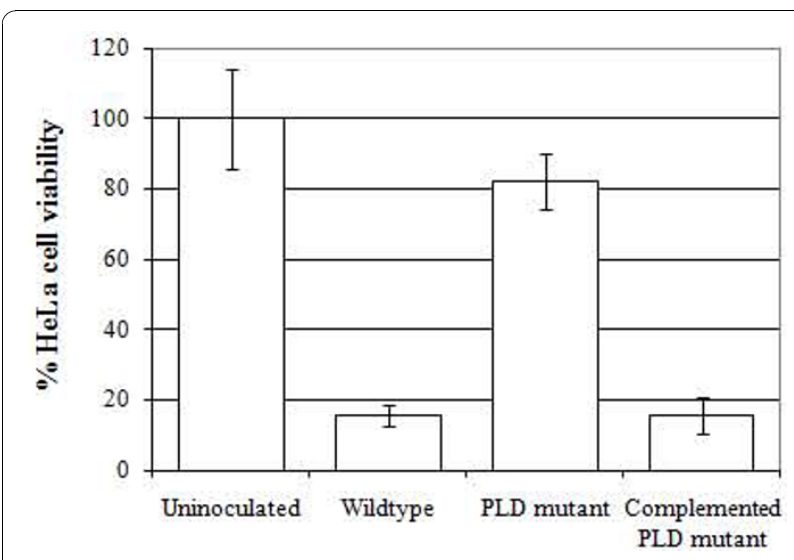

Figure 4 PLD expressed inside HeLa cells is cytotoxic. HeLa cells were inoculated with $A$. haemolyticum strains and the bacteria were allowed to adhere for $2 \mathrm{~h}$ and invade for $5 \mathrm{~h}$ prior to determination of host cell viability. Viability is shown as a percentage of that of diluent-treated cells, which was set to $100 \%$. Error bars indicate one standard deviation from the mean calculated from the averages of at least three independent experiments conducted in triplicate.

\section{A. haemolyticum PLD expressed inside HeLa cells results in host cell necrosis}

The mechanisms of host cell death following invasion of wild type A. haemolyticum were investigated. Apoptosis was determined by measurement of caspases $3 / 7,8$ and 9 activity, following inoculation of HeLa cells with $A$. haemolyticum strains. The levels of caspase $3 / 7,8$ or 9 activation of untreated HeLa cells were set at a nominal value of 1.0-fold caspase activity (Figure 5), and the values of caspase activation in HeLa cells inoculated with A. haemolyticum strains were compared to this. Staurosporine $(1 \mu \mathrm{M})$, used as a positive control, was able to induce apoptosis, as measured by 2.76 -fold, 1.27 -fold and 1.56 -fold increases in caspase $3 / 7,8$ and 9 activities, respectively ( $p<0.05$; Figure 5$)$. HeLa cells inoculated

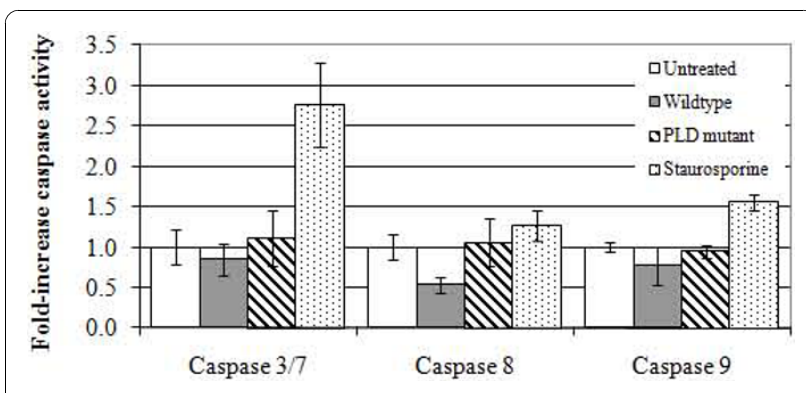

Figure 5 Intracellular PLD does not initiate apoptosis in HeLa cells. HeLa cells were inoculated with A. haemolyticum strains and the bacteria were allowed to adhere for $2 \mathrm{~h}$ and invade for $5 \mathrm{~h}$ prior to measurement of caspase $3 / 7,8$ or 9 activity. Activity is shown as a fold-change of untreated cells, which was set at a nominal value of 1.0. Error bars indicate one standard deviation from the mean calculated from the averages of at least three independent experiments conducted in triplicate. with wild type $A$. haemolyticum displayed no increase in apoptosis, as measured by caspase $3 / 7$ or 9 activity (1.12fold and 0.95-fold increases, respectively; Figure 5). However, HeLa cells inoculated with wild type A. haemolyticum had significantly reduced caspase 8 activity when compared to untreated cells (0.54-fold activity; $p<0.05$; Figure 5). HeLa cells inoculated with the pld mutant also displayed similar levels of caspase 3/7, 8 and 9 expression as the uninoculated HeLa cells (0.85-fold, 1.06-fold and 0.77 -fold, respectively; Figure 5). The caspase $3 / 7$ assay was repeated at 1 or $24 \mathrm{~h}$ post-invasion, however, no significant differences were observed in activity of these caspases at these time points (data not shown). Therefore, it appears that invasion of HeLa cells with A. haemolyticum strains was unable to induce apoptosis under these conditions (Figure 5).

As bacterial invasion did not induce apoptosis, it suggested that loss of HeLa cell viability may be due to necrosis. HeLa cells were inoculated with A. haemolyticum strains and examined by TEM. Uninoculated, control HeLa cells displayed normal architecture (Figure 6A). HeLa cells inoculated with the pld mutant displayed typical cellular architecture; however, bacteria could be observed in membrane-bound vacuoles within some cells (Figure 6B). In contrast, wild type inoculated cells appeared necrotic, as there was no membrane integrity, the cytoplasm appeared to be absent, the nucleus was condensed and the mitochondria were swollen (Figure 6C, D), all of which are hallmarks of cellular necrosis. Bacteria could be observed both in proximity to, and inside, the HeLa cells, and intracellular bacteria were not found within vacuoles (Figure 6C).

\section{Discussion and Conclusions}

Ceramides, including ceramide-1- $\mathrm{PO}_{4}$, are important mediators of a number of normal cellular signaling pathways such as cell growth, proliferation (including oncogenesis), apoptosis and inflammation via altered cytokine signaling [24]. While a number of bacteria express PLDs, there are only a few species expressing sphingomyelinases $\mathrm{D}$, which specifically cleave SM to ceramide-1- $\mathrm{PO}_{4}$ in host cell membranes. Given the central role of PLDs in normal host cell physiology, it is easy to see how the dysregulated release of ceramides from SM by bacterial PLDs could potentially lead to pleomorphic effects on the host cell [24], and how these effects could benefit the infection process.

We report the first molecular characterization of the PLD (sphingomyelinase D) from A. haemolyticum and show that the action of this enzyme has implications in the pathogenesis of disease caused by this organism. In a manner analogous to host PLDs [38], A. haemolyticum PLD was able to stimulate reorganization of lipid rafts in epithelial cell plasma membranes in a dose-dependent 


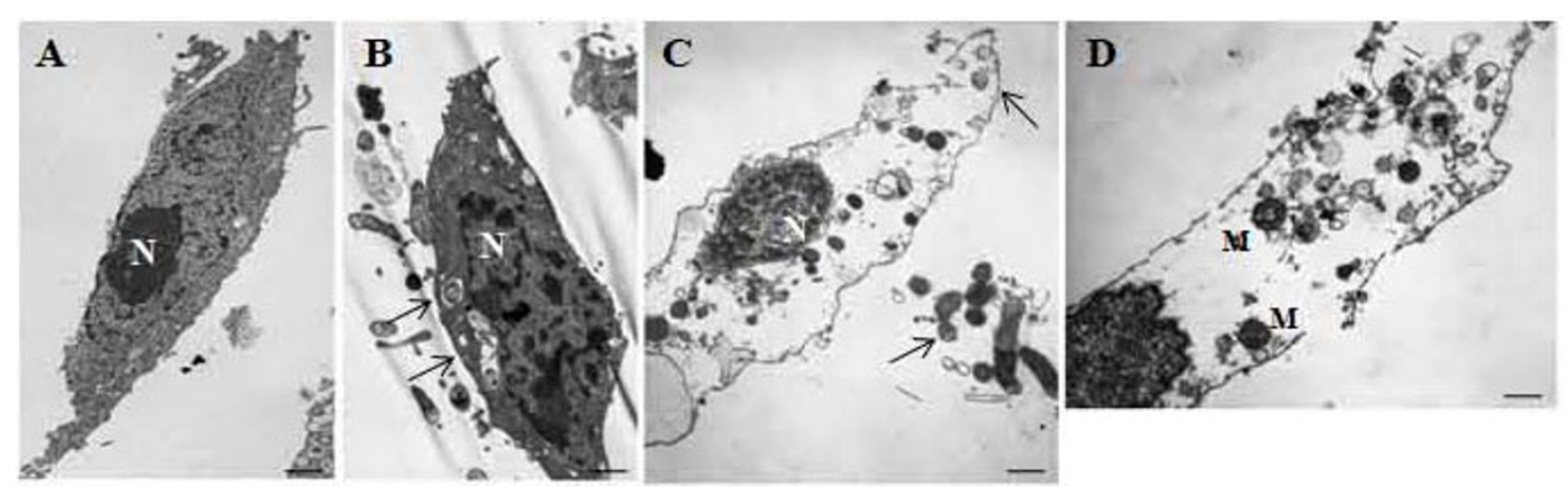

Figure 6 PLD apparently induces host cell damage by necrosis. Representative transmission electron micrographs of HeLa cells, (A) uninoculated, or inoculated with (B) A. haemolyticum pld mutant or (C, D) A. haemolyticum wild type using a standard invasion assay. Arrows indicate bacteria, $\mathrm{N}$ and $\mathrm{M}$ indicate the nucleus and mitochondria, respectively. The bars on the lower right indicates $\sim 1 \mu \mathrm{m}$.

manner (Figure 2C). This PLD-mediated lipid raft reorganization could be inhibited by anti-PLD antibodies, as well as by cholesterol sequestration (Figure 2D).

Recently, bacterially-induced lipid raft reorganization has been implicated in promoting efficient bacterial invasion rather than adhesion [39-42]. However, we observed that lipid raft rearrangement, mediated by PLD, directly promoted attachment to host cells, as an A. haemolyticum pld mutant had a $60.3 \%$ reduced adhesion as compared to the wild type (Figure 3A). It is unlikely that PLD, a secreted enzyme, acts directly as an adhesin. Furthermore, the hypothesis that PLD exposes a cryptic receptor, as seen with arcanobacterial neuraminidases [43], was also discarded as cholesterol sequestration by $\mathrm{M} \beta \mathrm{CD}$, which inhibits lipid raft rearrangement, also significantly reduces adhesion of $A$. haemolyticum to host cells (Figure 3A). A more likely explanation is that PLD-mediated lipid raft reorganization leads to protein clustering and increased local receptor concentrations [20], which in turn leads to enhanced bacterial adhesion. The nature of the host receptor and the adhesin on the bacterial cell is unknown, but the $A$. haemolyticum genome encodes at least one extracellular matrix binding (MSCRAMM) protein (B.H. Jost and S.J. Billington, unpublished data), which are known bacterial adhesins [44].

Expression of PLD by A. haemolyticum appears to negatively affect the ability of this organism to invade host cells, as the pld mutant has a more than 2 -fold increased ability to invade HeLa cells as compared to the wild type (Figure 3B). We hypothesized that rather than directly affecting invasion, invasion of host cells with $A$. haemolyticum strains expressing PLD had detrimental effects, such as loss of host cell viability. Cell death would expose bacteria to the extracellular gentamicin, leading to an observed increase in invasion with the pld mutant.
This appeared to be the case, as PLD expressed from wild type A. haemolyticum inside host cells resulted in $84.4 \%$ loss of cell viability as compared to untreated cells (Figure 4). This is in contrast to host cells invaded by the pld mutant, which had only a $17.7 \%$ loss of viability (Figure 4). Interestingly, when recombinant PLD is applied to the exterior of the host cell, it did not cause cytotoxicity, as measured by cell viability. This is not surprising in that PLD alone is unable to cause sufficient membrane perturbations to lyse non-nucleated cells such as erythrocytes [45]. Proper bacterial delivery of PLD to the host cell seems to be required for effects on host cell viability.

Apoptosis was not detected following A. haemolyticum invasion of HeLa cells (Figure 5). Of all the organelles, the outer leaflet of the mitochondrial membrane is particularly rich in SM [17], and we hypothesized that PLD may target this structure, possibly leading to caspase 9 activation as part of the mitochondrial apoptosis pathway. However, caspase 9 activation was not detected following A. haemolyticum invasion of HeLa cells, nor was the activation of caspase $3 / 7$ or 8 , which are measures of general apoptosis or the extrinsic apoptosis pathway, respectively. We note that the findings from these apoptosis studies must be tempered with caution in that they were performed in a cell line, and may not accurately reflect what is occurring in host tissue.

The TEM study confirms the intracellular invasion of HeLa cells by $A$. haemolyticum and indicates that the pld mutant is unable to escape the invasion vacuole, at least by the measured time point (Figure 6B). In contrast, the wild type is able to escape the vacuole (Figure 6C) and can cause host cell death (Figure 4), apparently by necrosis (Figure 6C, D). Direct measurement of necrosis has been difficult, and has traditionally used changes to cellular architecture rather than specific biomarkers. However, better data is emerging about of the 
types of cell processes that initiate necrosis within the host cell, and recently it was determined that PLDmediated release of ceramides can play a central role in initiating cellular necrosis [46].

Necrosis as a cause of host cell death may not be surprising given that a hallmark of $A$. haemolyticum pharyngitis is localized inflammation [2]. Necrosis-induced inflammation may enhance the immune response or cause localized tissue damage which promotes bacterial dissemination. The balance of these possibilities may be tipped towards bacterial invasion in the case of individuals who are also immunocompromised, elderly or have other co-morbid factors, leading to the more invasive sequelae observed with $A$. haemolyticum infections in this patient population [8-13].

From these studies we conclude that PLD expressed by $A$. haemolyticum is responsible for efficient host cell adhesion by reorganizing lipid rafts, which presumably clusters adhesin receptors. However, the identity of the host and bacterial receptors are currently unknown. PLD is also required following invasion into host cells. The pld mutant appears to be defective in that it cannot or is significantly delayed in its ability to escape the invasion vacuole, which leads to increased host cell viability. In contrast, the PLD-expressing wild type $A$. haemolyticum presumably escapes the vacuole, and PLD expressed inside the host cell causes cellular necrosis. The mechanism(s) by which $A$. haemolyticum PLD acts to cause necrosis are unknown. Host PLDs have a plethora of activities inside the cells [24], and dysregulated expression of bacterial PLD could lead to pleomorphic effects, any number of which could lead to the cellular signals for necrosis. Alternatively, PLD could trigger a specific necrotic response in the cell or PLD could actively block apoptosis, leading to a "forced" necrosis pathway [46]. Which of these hypotheses is correct remains to be elucidated with further study.

\section{Methods}

\section{Bacterial strains and growth conditions}

The type strain of $A$. haemolyticum (ATCC9345) was used for all experiments. The other A. haemolyticum strains were clinical isolates $(n=52)$ obtained from either throat or wound swabs and were grown on tryptic soy (TS) agar plates supplemented with $5 \%$ bovine blood at $37^{\circ} \mathrm{C}$ and $5 \% \mathrm{CO}_{2}$ or in TS broth supplemented with $10 \%$ newborn calf serum (Atlas Biologicals) at $37^{\circ} \mathrm{C}$ with shaking. Escherichia coli DH5 $\alpha$ MCR strains (GibcoBRL) were grown on Luria-Bertani (LB) agar or in LB broth at $37^{\circ} \mathrm{C}$. Antibiotics were added as appropriate: for A. haemolyticum, kanamycin (Kn) at $200 \mu \mathrm{g} / \mathrm{ml}$, chloramphenicol $(\mathrm{Cm})$ at $5 \mu \mathrm{g} / \mathrm{ml}$; for $E$. coli, ampicillin at $100 \mu \mathrm{g} / \mathrm{ml}, \mathrm{Cm}$ at $30 \mu \mathrm{g} / \mathrm{ml}, \mathrm{Kn}$ at $50 \mu \mathrm{g} / \mathrm{ml}$.
PLD production by $A$. haemolyticum isolates was identified by the presence of synergistic hemolysis following growth on TS agar plates with $5 \%$ bovine blood and $10 \%$ Equi Factor, as PLD is not hemolytic alone. Equi Factor was prepared from the $0.2 \mu \mathrm{m}$ filtered supernatant of an overnight culture of Rhodococcus equi ATCC6939 [45]. Samples of A. haemolyticum ATCC9345 broth culture were harvested at points throughout the growth cycle. Culture supernatants were obtained by centrifugation and $0.2 \mu \mathrm{m}$ filtration, and stored at $-80^{\circ} \mathrm{C}$ prior to assay for PLD activity. Wells were punched into TS agar containing $5 \%$ bovine blood and $10 \%$ Equi Factor and $20 \mu \mathrm{l}$ of culture supernatant was added. Zones of hemolysis were measured after $4 \mathrm{~h}$ incubation at $37^{\circ} \mathrm{C}$.

\section{DNA techniques and sequence analysis}

E. coli plasmid DNA extraction, DNA restriction, ligation, transformation, agarose gel electrophoresis and Southern transfer of DNA were performed as described [47]. Genomic DNA isolation and electroporationmediated transformation of $A$. haemolyticum strains was performed as previously described for A. pyogenes [48], except that a capacitance of $25 \mu \mathrm{F}$ and a resistance of $200 \Omega$ were used. PCR DNA amplification was performed using Taq or Vent DNA polymerase (NEB) with the supplied reaction buffer for 35 cycles consisting of 1 $\min$ at $94^{\circ} \mathrm{C}, 1 \mathrm{~min}$ at $55^{\circ} \mathrm{C}$, and $1 \mathrm{~min} / \mathrm{kb}$ at $72^{\circ} \mathrm{C}$. Preparation of DNA probes, DNA hybridization, and probe detection were performed using a DIG DNA Labeling and Detection Kit (Roche).

Database searches were performed using the BlastX and BlastP algorithms [49]. tRNA sequences were identified using the tRNAscan-SE program [50]. Signal sequence prediction was performed using SignalP [51]. Transcriptional terminators were identifier using mfold [52].

\section{Cloning and purification of a recombinant, $6 \times \mathrm{His}$ tagged- PLD (HIS-PLD)}

The pld gene, lacking the signal sequence coding region, was amplified from A. haemolyticum ATCC9345 genomic DNA by PCR with a 5 ' primer containing a $B a m \mathrm{HI}$ site (5'-CGGCTGCGGATCCACTTGCGCAAGAACAACC-3') and a 3' primer containing an EcoRI site (5'ATAAGAATTCGTGTTATCTCATTCG-3'; underlined in sequence). These primers amplified an 886 -bp product from bases 94-940 of the pld gene, which was cloned into pTrcHis B (Invitrogen) to generate pBJ31, encoding HIS-PLD. Cultures for purification of HISPLD were grown to an $\mathrm{OD}_{600}=0.6$ prior to induction with $2.5 \mathrm{mM}$ IPTG for $3 \mathrm{~h}$ and harvested by centrifugation. Cells were solubilized in $8 \mathrm{M}$ urea at $4^{\circ} \mathrm{C}$ overnight with gentle agitation. HIS-PLD was purified from the 
soluble material using TALON metal affinity resin (Clontech), and eluted from the resin with $150 \mathrm{mM}$ imidazole in $20 \mathrm{mM}$ Tris- $\mathrm{HCl}, 100 \mathrm{mM} \mathrm{NaCl}, \mathrm{pH}$ 8.0. Purified HIS-PLD was mixed 1:1 with SDS-sample buffer and boiled for 5 min prior to electrophoresis in a $10 \%$ $(w / v)$ SDS-polyacrylamide gel [47]. Proteins were transferred to nitrocellulose and Western blots were immunostained using rabbit anti-HIS-PLD (prepared by immunization of a rabbit with HIS-PLD; Antibodies Inc.) and goat anti-rabbit $\operatorname{IgG}(\mathrm{H}+\mathrm{L})$-peroxidase conjugate (KPL) as the primary and secondary antibodies, respectively [47]. SDS-PAGE and Coomassie Blue staining of purified HIS-PLD yielded a band of approximately $35.5-\mathrm{kDa}$ and showed greater than $>95 \%$ purity. Antiserum against PLD, but not pre-immune antiserum, reacted specifically with HIS-PLD (data not shown). Purified HIS-PLD retained hemolytic activity as demonstrated by PLD activity assay (data not shown). Total protein concentration was determined with Bradford protein assay reagent (Bio-Rad). Endotoxin contamination of HIS-PLD preparations was determined using the Limulus Amebocyte Lysate Pyrogent Kit (Cambrex), and endotoxin levels were negligible $(<0.06 \mathrm{EU} / \mathrm{ml}$; data not shown).

\section{Construction of a pld knockout mutant and a complementing plasmid}

The pld gene was amplified from A. haemolyticum ATCC 9345 by PCR using forward and reverse primers (5'-GTGTAAGCTTCAACATAGAGACATGG-3') and (5'-ATAAGAATTCGTGTTATCTCATTCG-3'). The PCR product was digested with HindIII-EcoRI using restriction sites engineered into the primers (underlined in sequence) and cloned into similarly digested pBC KS (Stratagene), to construct pBJ29. The pld gene in pBJ29 was interrupted by insertion with a 1.4-kb BamHI fragment carrying the Kn resistance gene from pKRP11 [53], which allows for the construction of non-polar mutations. This plasmid was used to transform A. haemolyticum ATCC9345, selecting for $\mathrm{Kn}^{\mathrm{R}} \mathrm{Cm}^{\mathrm{S}}$ colonies. Southern blot analysis of $A$. haemolyticum wild type and pld- mutant genomic DNA confirmed inactivation of the pld gene via a double cross-over event (data not shown). A pld complementing plasmid, pBJ61, was constructed by cloning the insert of pBJ29 into pJGS180 [43], which replicates in A. haemolyticum (data not shown).

\section{Tissue culture cell adhesion and invasion assays}

HeLa cells were cultured in Iscove's Modified Dulbecco's Medium with $10 \%$ fetal calf serum (IMDM-10\% FCS) with $10 \mu \mathrm{g} / \mathrm{ml}$ gentamicin at $37^{\circ} \mathrm{C}$ and at $5 \% \mathrm{CO}_{2}$. For adhesion assays, cells in IMDM-10\% FCS, without gentamicin, were seeded into 24 -well plates at $2 \times 10^{5}$ cells/well in $1 \mathrm{ml}$ volumes. The cells were incubated overnight prior to the addition of log-phase A. haemolyticum at a multiplicity of infection (MOI) of 10:1. Bacterial adhesion was assessed after $2 \mathrm{~h}$ at $37^{\circ} \mathrm{C}$. Cell monolayers were washed three times with $0.1 \mathrm{M}$ phosphate-buffered saline, $\mathrm{pH} 7.2$ (PBS) to remove nonadherent bacteria. Cell monolayers were lysed using 1 $\mathrm{ml}$ ice-cold $0.1 \%$ Triton X-100 for $10 \mathrm{~min}$, and viable bacteria were enumerated by dilution plating. To assess the inhibitory affect of the cholesterol sequestering agent methyl-beta-cyclodextrin (M $\beta C D$; Sigma) on adhesion, $5 \mathrm{mM} \mathrm{M} \beta C D$ was added to HeLa cells for 40 min prior to addition of bacteria, as described above, and maintained at $5 \mathrm{mM}$ in the medium for the duration of the experiment. To assess the effect of exogenous PLD, 312 ng HIS-PLD was added to HeLa cells for $10 \mathrm{~min}$ prior to the addition of bacteria, as described above.

For invasion assays, bacteria were added at an MOI of 20:1, were allowed to adhere and invade for $2 \mathrm{~h}$, at which time the cell monolayers were washed three times with Hank's Balanced Salt Solution, and IMDM-10\% FCS containing $10 \mu \mathrm{g} / \mathrm{ml}$ gentamicin was added to the wells. The plates were incubated for an additional $2 \mathrm{~h}$ to allow invasion and killing of extracellular bacteria. The monolayers were washed and internalized bacteria were recovered and enumerated as above.

\section{Epithelial cell cytotoxicity}

The cytotoxicity of HIS-PLD for epithelial cells was determined using the CellTiter $96^{\circ}$ Aqueous One Solution Cell Proliferation Assay (Promega). HeLa cells were seeded into 96-well plates at $2 \times 10^{4}$ cells/well and the cells were incubated for $18 \mathrm{~h}$ to achieve $80 \%$ confluence. Triplicate wells were incubated with doubling dilutions of HIS-PLD $(0-2 \mu \mathrm{g})$ and incubated for $2-24 \mathrm{~h}$, as above. Dilutions of imidazole-containing HIS-protein elution buffer were used as a control. Additional monolayers were inoculated with log-phase A. haemolyticum strains at an MOI of 20:1, and incubated for $2 \mathrm{~h}$, as above. The monolayers were washed three times with PBS and IMDM-10\% FCS containing $10 \mu \mathrm{g} / \mathrm{ml}$ gentamicin was added and the cells were incubated for a further $5 \mathrm{~h}$. 3-(4,5-dimethylthiazol-2-yl)-5-(3-carboxymethoxyphenyl)-2-(4-sulfophenyl)-2H-tetrazolium/phenazine methosulfate (MTS/PMS) reagent was added and the HeLa cells were incubated for an additional $3 \mathrm{~h}$. The color change was measured at $492 \mathrm{~nm}$ using a Synergy HT plate reader (Bio-Tek). Determination of \% cell viability was performed using the appropriate control values, as described by the manufacturer.

\section{Lipid raft labeling}

HeLa cells were seeded into 8-well chamber slides (LabTek) at $1 \times 10^{4}$ cells/well and were incubated overnight 
to achieve $70 \%$ confluence. The cells were washed with PBS prior to incubation with dilutions of HIS-PLD (0$50 \mathrm{ng}$ ) for $10 \mathrm{~min}$ at $37^{\circ} \mathrm{C}$ and $5 \% \mathrm{CO}_{2}$. Dilutions of imidazole-containing elution buffer were used as a control. Lipid rafts were labeled using the Vybrant $^{\circ}$ Lipid Raft Labeling Kit (Molecular Probes). The slides were mounted in 2\% 1,4-diazabicyclo [2.2.2] octane (DABCO; Sigma) in 50\% glycerol and visualized with a Nikon epifluorescence microscope fitted with a rhodamine filter.

To assess the inhibitory effect of specific antibody, 1/ 1000 dilutions of anti-PLD or pre-immune serum were incubated with $50 \mathrm{ng}$ HIS-PLD for $1 \mathrm{~h}$ at $37^{\circ} \mathrm{C}$ prior to addition of the mixture to the HeLa cell monolayer. To assess the effect of cholesterol sequestration, $5 \mathrm{mM}$ $\mathrm{M} \beta C D$ was added to HeLa cells for $40 \mathrm{~min}$ at $37^{\circ} \mathrm{C}$ and $5 \% \mathrm{CO}_{2}$ prior to stimulation of the cells with $50 \mathrm{ng}$ HIS-PLD. PLD enzymatic activity was not inhibited by the presence of $5 \mathrm{mM} \mathrm{M \beta CD}$ (data not shown).

\section{Transmission electron microscopy (TEM)}

HeLa cell monolayers were inoculated and incubated as for the invasion assay described above. The cells were harvested by scraping and were fixed with $4 \%$ formaldehyde- $1 \%$ glutaraldehyde in PBS, embedded in Epon-Araldite, postfixed with $1 \%$ osmium tetroxide and stained with $5 \%$ uranyl acetate. Thin sections $(50 \mathrm{~nm})$ were examined using a Philips CM-12 electron microscope at an accelerating voltage of $60 \mathrm{kV}$.

\section{Apoptosis assays}

HeLa cells were seeded into 96 -well plates at $2 \times 10^{4}$ cells/well and the cells were incubated overnight to achieve $80 \%$ confluence. Triplicate wells were inoculated with $A$. haemolyticum strains, as described above for the epithelial cell cytotoxicity assay. Apoptosis was measured using the Caspase-Glo 3/7, 8 or 9 Assay Systems (Promega). HeLa cells were incubated with $1 \mu \mathrm{M}$ staurosporine (Sigma) to induce apoptosis, as a positive control.

\section{Statistical analysis}

Statistical significance was determined at the $p<0.05$ level with single factor ANOVA, calculated using Microsoft Excel.

\section{Nucleotide sequence accession number}

The pld gene region sequence data were submitted to the GenBank/EMBL/DDBJ databases under accession number FJ766092.

\section{Acknowledgements}

The authors acknowledge Maricela V. Pier, Stephanie E. Hastings and Ryan G. Miller, University of Arizona for excellent technical assistance and Deborah A. Schaefer for advice with fluorescence microscopy. Support for this work was provided by USDA Hatch ARZT-136828-H-02-129 and the College of Agriculture and Life Sciences, University of Arizona to BHJ and SJB.

\section{Author details}

${ }^{1}$ Department of Veterinary Science and Microbiology, The University of Arizona, 1117 E Lowell Street, Tucson, AZ 85721, USA. ²Department of Bacteriology and Immunology, Haartman Institute, University of Helsinki, Haartmaninkatu 3, P.O. Box 21, Helsinki, FIN-00014, Finland. ${ }^{3}$ Department of Microbiology and Immunology, Louisiana State University Health Sciences Center-Shreveport, 1501 Kings Highway, Shreveport, LA 71130, USA. ${ }^{4}$ Modesto Junior College, 435 College Avenue, Modesto, CA 95350, USA. ${ }^{5}$ Ventana Medical Systems, Inc., 1910 Innovation Park Drive, Oro Valley, AZ 85755, USA. ${ }^{6}$ Office for the Responsible Conduct of Research, The University of Arizona, P.O. Box 245092, Tucson, AZ 85721, USA.

\section{Authors' contributions}

EL conducted the bulk of the experiments and wrote the first draft of the manuscript; SJB constructed the pld mutant and provided scientific discussion; PC provided clinical isolates. DJM edited and submitted the manuscript; BHJ did the initial characterization of PLD activity on RBCs, provided scientific guidance and discussion and wrote the completed manuscript. All authors read and approved the final manuscript.

Received: 7 May 2010 Accepted: 25 October 2010

Published: 25 October 2010

\section{References}

1. Collins MD, Jones D, Schofield GM: Reclassification of 'Corynebacterium haemolyticum' (MacLean, Liebow \& Rosenberg) in the genus Arcanobacterium gen. nov. as Arcanobacterium haemolyticum nom. rev., comb. nov. J Gen Microbiol 1982, 128:1279-1281.

2. MacLean PD, Liebow AA, Rosenberg AA: A haemolytic bacterium resembling Corynebacterium ovis and Corynebacterium pyogenes in man. J Infect Dis 1946, 79:69-90.

3. Jost $\mathrm{BH}$, Billington $\mathrm{SJ}$ : Arcanobacterium pyogenes: molecular pathogenesis of an animal opportunist. Antonie van Leeuwenhoek 2005, 88:87-102.

4. Banck G, Nyman M: Tonsillitis and rash associated with Corynebacterium haemolyticum. J Infect Dis 1986, 154:1037-1040.

5. Miller RA, Brancato F, Holmes KK: Corynebacterium haemolyticum as a cause of pharyngitis and scarlatiniform rash in young adults. Ann Intern Med 1986, 105:867-872.

6. Waagner DC: Arcanobacterium haemolyticum: biology of the organism and diseases in man. Pediatr Infect Dis J 1991, 10:933-939.

7. Carlson P, Renkonen OV, Kontiainen S: Arcanobacterium haemolyticum and streptococcal pharyngitis. Scand J Infect Dis 1994, 26:283-287.

8. Minarik T, Sufliarsky J, Trupl J, Krcmery V Jr: Arcanobacterium haemolyticum invasive infections, including meningitis in cancer patients. J Infect 1997, 34:91.

9. Goyal R, Singh NP, Mathur M: Septic arthritis due to Arcanobacterium haemolyticum. Indian J Med Microbiol 2005, 23:63-65.

10. Biswas D, Gupta P, Gupta P, Prasad R, Arya M: A case of chronic osteomyelitis due to Arcanobacterium haemolyticum. Indian J Med Microbiol 2003, 21:209-210.

11. Tan TY, Ng SY, Thomas H, Chan BK: Arcanobacterium haemolyticum bacteraemia and soft-tissue infections: Case report and review of the literature. J Infect 2005, 53:69-74.

12. Skov RL, Sanden AK, Danchell VH, Robertsen K, Ejlertsen T: Systemic and deep-seated infections caused by Arcanobacterium haemolyticum. Eur J Clin Microbiol Infect Dis 1998, 17:578-582.

13. White $\mathrm{CB}$, Foshee WS: Upper respiratory tract infections in adolescents. Adolescent Medicine 2000, 11:225-249.

14. Soucek A, Souckova A: Toxicity of bacterial sphingomyelinases D. J Hyg Epidemiol Microbiol Immunol 1974, 18:327-335.

15. Votava M, Skalka B, Woznicova V, Ruzicka F, Zahradnicek O, Ondrovcik P, Klapacova L: Detection of Arcanobacterium haemolyticum phospholipase D neutralizing antibodies in patients with acute tonsillitis. Epidemiol Mikrobiol Imunol 2001, 50:111-116.

16. Skalka B, Literak I, Chalupa P, Votava M: Phospholipase D-neutralization in serodiagnosis of Arcanobacterium haemolyticum and Corynebacterium pseudotuberculosis infections. Zentralbl Bakteriol 1998, 288:463-470. 
17. Andreoli TE: Physiology of membrane disorders. New York: Plenum Medical Book Co, 21987

18. Sengupta P, Baird B, Holowka D: Lipid rafts, fluid/fluid phase separation, and their relevance to plasma membrane structure and function. Semin Cell Dev Biol 2007, 18:583-590.

19. Zaas DW, Duncan M, Rae Wright J, Abraham SN: The role of lipid rafts in the pathogenesis of bacterial infections. Biochim Biophys Acta 2005, 1746:305-313.

20. Zhang Y, Li X, Becker KA, Gulbins E: Ceramide-enriched membrane domains-Structure and function. Biochim Biophys Acta 2009, 1788:178-183.

21. Cuevas WA, Songer JG: Arcanobacterium haemolyticum phospholipase D is genetically and functionally similar to Corynebacterium pseudotuberculosis phospholipase D. Infect Immun 1993, 61:4310-4316.

22. Jenkins GM, Frohman MA: Phospholipase D: a lipid centric review. Cell Molec Life Sci 2005, 62:2305-2316.

23. van Meeteren LA, Frederiks F, Giepmans BN, Pedrosa MF, Billington SJ, Jost BH, Tambourgi DV, Moolenaar WH: Spider and bacterial sphingomyelinases $D$ target cellular lysophosphatidic acid receptors by hydrolyzing lysophosphatidylcholine. J Biol Chem 2004, 279:10833-10836.

24. El Alwani M, Wu BX, Obeid LM, Hannun YA: Bioactive sphingolipids in the modulation of the inflammatory response. Pharmacol Ther 2006, 112:171-183.

25. McNamara PJ, Bradley GA, Songer JG: Targeted mutagenesis of the phospholipase $D$ gene results in decreased virulence of Corynebacterium pseudotuberculosis. Molec Microbiol 1994, 12:921-930.

26. Tambourgi DV, De Sousa Da Silva M, Billington SJ, Goncalves De Andrade RM, Magnoli FC, Songer JG, Van Den Berg CW: Mechanism of induction of complement susceptibility of erythrocytes by spider and bacterial sphingomyelinases. Immunology 2002, 107:93-101.

27. Yozwiak ML, Songer JG: Effect of Corynebacterium pseudotuberculosis phospholipase $\mathrm{D}$ on viability and chemotactic responses of ovine neutrophils. Am J Vet Res 1993, 54:392-397.

28. Murakami MT, Fernandes-Pedrosa MF, Tambourgi DV, Arni RK: Structural basis for metal ion coordination and the catalytic mechanism of sphingomyelinases D. J Biol Chem 2005, 280:13658-13664.

29. Tambourgi DV, Petricevich VL, Magnoli FC, Assaf SL, Jancar S, Da Silva WD: Endotoxemic-like shock induced by Loxosceles spider venoms: pathological changes and putative cytokine mediators. Toxicon 1998, 36:391-403.

30. Tambourgi DV, Magnoli FC, van den Berg CW, Morgan BP, de Araujo PS, Alves EW, Da Silva WD: Sphingomyelinases in the venom of the spider Loxosceles intermedia are responsible for both dermonecrosis and complement-dependent hemolysis. Biochem Biophys Res Comm 1998, 251:366-373.

31. Wilderman PJ, Vasil Al, Johnson Z, Vasil ML: Genetic and biochemical analyses of a eukaryotic-like phospholipase $D$ of Pseudomonas aeruginosa suggest horizontal acquisition and a role for persistence in a chronic pulmonary infection model. Molec Microbiol 2001, 39:291-303.

32. Renesto P, Dehoux P, Gouin E, Touqui L, Cossart P, Raoult D: Identification and characterization of a phospholipase D-superfamily gene in rickettsiae. J Infect Dis 2003, 188:1276-1283.

33. Nelson DE, Crane DD, Taylor LD, Dorward DW, Goheen M, Caldwell HD: Inhibition of chlamydiae by primary alcohols correlates with the strainspecific complement of plasticity zone phospholipase D genes. Infect Immun 2006, 74:73-80.

34. Johansen KA, Gill RE, Vasil ML: Biochemical and molecular analysis of phospholipase $C$ and phospholipase D activity in mycobacteria. Infect Immun 1996, 64:3259-3266.

35. Edwards JL, Entz DD, Apicella MA: Gonococcal phospholipase D modulates the expression and function of complement receptor 3 in primary cervical epithelial cells. Infect Immun 2003, 71:6381-6391.

36. Williams KP: Integration sites for genetic elements in prokaryotic tRNA and tmRNA genes: sublocation preference of integrase subfamilies. NuCl Acids Res 2002, 30:866-875.

37. Ilangumaran S, Hoessli DC: Effects of cholesterol depletion by cyclodextrin on the sphingolipid microdomains of the plasma membrane. Biochem J 1998, 335:433-440.

38. Gulbins E, Li PL: Physiological and pathophysiological aspects of ceramide. Am J Physiol Regul Integr Comp Physiol 2006, 290:R11-R26.

39. Abraham SN, Duncan MJ, Li G, Zaas D: Bacterial penetration of the mucosal barrier by targeting lipid rafts. J Investig Med 2005, 53:318-321.
40. Goluszko P, Popov V, Wen J, Jones A, Yallampalli C: Group B streptococcus exploits lipid rafts and phosphoinositide 3-kinase/Akt signaling pathway to invade human endometrial cells. Am J Obstet Gynecol 2008, 199:548. e541-548.e549.

41. Tsuda K, Furuta N, Inaba H, Kawai S, Hanada K, Yoshimori T, Amano A: Functional analysis of a $5 \beta 1$ integrin and lipid rafts in invasion of epithelial cells by Porphyromonas gingivalis using fluorescent beads coated with bacterial membrane vesicles. Cell Struct Funct 2008 33:123-132.

42. Seveau S, Bierne H, Giroux S, Prévost MC, Cossart P: Role of lipid rafts in Ecadherin- and HGF-R/Met-mediated entry of Listeria monocytogenes into host cells. J Cell Biol 2004, 166:743-753.

43. Jost BH, Songer JG, Billington SJ: Identification of a second Arcanobacterium pyogenes neuraminidase, and involvement of neuraminidase activity in host cell adhesion. Infect Immun 2002, 70:1106-1112.

44. Talay SR: Gram-positive adhesins. In Concepts in bacterial virulence. Edited by: Russell W, Herwald H. Basel: Karger; 2005:12:90-113.

45. Linder R, Bernheimer AW: Enzymatic oxidation of membrane cholesterol in relation to lysis of sheep erythrocytes by corynebacterial enzymes. Arch Biochem Biophys 1982, 213:395-404

46. Henriquez M, Armisén R, Stutzin A, Quest AF: Cell death by necrosis, a regulated way to go. Curr Molec Med 2008, 8:187-206.

47. Ausubel FM, Brent R, Kingston RE, Moore DD, Seidman JG, Smith JA, Struhl K: Current protocols in molecular biology. New York, NY: Greene Publishing Associates and John Wiley and Sons, Inc 1994, 1.

48. Jost BH, Billington SJ, Songer JG: Electroporation-mediated transformation of Arcanobacterium (Actinomyces) pyogenes. Plasmid 1997, 38:135-140.

49. Altschul SF, Madden TL, Schäffer AA, Zhang J, Zhang Z, Miller W, Lipman DJ: Gapped BLAST and PSI-BLAST: a new generation of protein database search programs. Nucleic Acids Res 1997, 25:3389-3402.

50. Lowe TM, Eddy SR: tRNAscan-SE: a program for improved detection of transfer RNA genes in genomic sequence. Nucl Acids Res 1997, 25:955-964.

51. Nielsen H, Engelbrecht J, Brunak S, von Heijne G: Identification of prokaryotic and eukaryotic signal peptides and prediction of their cleavage sites. Protein Eng 1997, 10:1-6.

52. Zucker M: Mfold web server for nucleic acid folding and hybridization prediction. Nucl Acids Res 2003, 31:3406-3415.

53. Reece KS, Phillips GJ: New plasmids carrying antibiotic resistance cassettes. Gene 1995, 165:141-142.

\section{doi:10.1186/1471-2180-10-270}

Cite this article as: Lucas et al:: Phospholipase D promotes

Arcanobacterium haemolyticum adhesion via lipid raft remodeling and

host cell death following bacterial invasion. BMC Microbiology 2010 $10: 270$.

\section{Submit your next manuscript to BioMed Central and take full advantage of:}

- Convenient online submission

- Thorough peer review

- No space constraints or color figure charges

- Immediate publication on acceptance

- Inclusion in PubMed, CAS, Scopus and Google Scholar

- Research which is freely available for redistribution

Submit your manuscript at www.biomedcentral.com/submit
Biomed Central 